\title{
THE ROLE OF L-TYPE CALCIUM CHANNELS IN THE MEDIATION OF FAST OSCILLATION OF ARTERIAL BLOOD PRESSURE AND RENAL BLOOD FLOW IN RATS
}

\author{
P. Markova*, R. Girchev \\ Department of Physiology, Medical Faculty, Medical University-Sofia, Sofia, Bulgaria
}

\begin{abstract}
The investigation of dynamic characteristics of blood pressure and renal blood flow provides detailed information about the fast regulatory mechanisms involved in arterial blood pressure (ABP) and renal blood flow (RBF) autoregulation. The aim of our study was to investigate the role of L-type $\mathrm{Ca}^{2+}$ channels in the mediation of fast oscillations of arterial blood pressure and renal blood flow in rats by means of spectral analysis. The experiments were performed on anesthetized male Wistar rats $(n=7)$ at the age of 12-14 weeks. The ABP was measured directly in femoral artery; RBF was registered by perivascular ultrasonic Doppler probe (Transonic system) in control and experimental period. The spectrograms from APB and RBF were derived in Lab View 3.11 software. In experimental period the selective L-type $\mathrm{Ca}^{2+}$ channel blocker amlodipine besylate (AML) in dose $200 \mathrm{mkg} \cdot \mathrm{kg}^{-1}$ bolus followed by $50 \mathrm{mkg} \cdot \mathrm{kg}^{-1}$.h infusions was applied. Our results by using a spectral method of analysis of ABP and RBF confirmed involvement of L-type $\mathrm{Ca}^{2+}$ channels in the mediation of dynamic nature of myogenic vascular response. The L-type $\mathrm{Ca}^{2+}$ channels in different specific manner participate in the regulation of renal blood flow and arterial blood pressure.
\end{abstract}

Key word: spectral analysis, amlodipine besylate, perivascular ultrasonic Doppler probe

\section{INTRODUCTION}

Autoregulation of blood flow is described as a function of the vascular system that provides constant tissue perfusion regardless of changes in blood pressure. This function is presented in almost any tissue but is particularly pronounced in the kidney. Autoregulation of renal blood flow has been determined by two main mechanisms: renal myogenic response and tubuloglomerular feedback mechanism. Myogenic vascular responses were first described by Sir William Bayliss (1) and are characterized by a vasoconstriction if perfusion pressure increases and by a vasodilatation if perfusion pressure decreases. Despite of intensive investigation, identification of the mechanosensors responsible for initiating the myogenic response and many aspects of the

\footnotetext{
*Correspondence to: Petya Markova, Department of Physiology, Medical Faculty, Medical University-Sofia, Sofia-1431Boul. "G. Sofiiski" 1, Tel: +35929172550, e-mail: pp.markova@gmail.com
}

signaling pathways remain uncertain. The mechanism of the myogenic vascular response involves pressure-induced depolarization of the cell membrane, followed by opening of voltage-gate $\mathrm{L}$-type $\mathrm{Ca}^{2+}$ channels $(2,3)$. It has been established a high expression of L-type $\mathrm{Ca}^{2+}$ channels in the renal vessels. The experimental administration of amlodipine, a calcium inhibitor from the nifedipine group, predominantly affecting L-type $\mathrm{Ca}^{2+}$ channels, can be used as an assay that largely eliminates the myogenic component of autoregulation of renal blood flow (4). The available experimental data of investigation of blood pressure variability (BPV), an approach that provides important information about cardiovascular regulation (5-9), give grounds for admitting that oscillations between 0.02$0.2 \mathrm{~Hz}$ (LF) is generated by myogenic vascular responses to spontaneously occurring perturbations of blood pressure (9). Studies of renal blood flow dynamics established that myogenic response of the afferent arterioles 
accounts for most of the rapid compensation to changes in arterial pressure in the range of 0.1 to $0.3 \mathrm{~Hz}(10,11)$. Mid frequency (MF) blood pressure fluctuations $(0.2-0.6 \mathrm{~Hz}$ in rats $)$, have been associated mostly with sympathetic modulation of vascular tone $(5,6,8)$. It has been established that sympathetic modulation of vascular tone is partly mediated by L-type $\mathrm{Ca}^{2+}$ channels as well as myogenic vascular responce $(8,9,10)$. High frequency (HF) blood pressure variability $(0.2-0.6 \mathrm{~Hz}$ in rats), has been suggested to involve fluctuations in cardiac output (7).

Studies designed to assess RBF autoregulation involves measurement of RBF in response to changes of blood pressure. Different experimental approaches have been used to assess different aspect or renal blood flow autoregulation (11). However the available experimental data about RBF auteregulation obtained by steady-state, different kinetics and dynamics approaches in many cases are opposite $(2,11)$. Both ABP and RBF oscillated around to its optimal mean values. The investigation of dynamic characteristics of blood pressure and renal blood flow provides detailed information about the fast regulatory mechanisms involved in $\mathrm{ABP}$ and $\mathrm{RBF}$ autoregulation.

The aim of our study was to investigate the role of L-type $\mathrm{Ca}^{2+}$ channels in the mediation of fast oscillations of arterial blood pressure and renal blood flow in rats be means of spectral analysis.

\section{MATERIALS AND METHOD}

The experiments were performed on anesthetized male Wistar rats $(n=7)$ at the age of 12-14 weeks. Animals were bred and raised in the Vivarium of the Faculty of Medicine under standard laboratory conditions: 12/12 light / dark period; free access to drinking water and food in a ventilated room with constant access to fresh air. The experiments were carried out under conditions corresponding to requirements for experimental work with experimental animals (BAFS license №142/03.08.2016).

Under general anesthesia (Nembutal $35 \mathrm{mg} /$ $\mathrm{kg}$, i.p.) the femoral artery for direct registration of arterial blood pressure and femoral vein for drug application were catheterized. A perivascular ultrasonic Doppler probe (Transonic system) to monitor blood flow in the renal artery was implanted by retroperitoneal access.
MARKOVA P. et al. After the adaptation period required stabilizing the investigated parameters, under conditions of constant narcotic depth (infusion of Nembutal $3.5 \mathrm{mg} / \mathrm{kg}$, i.v.) and constant optimal body temperature, in a control and experimental period, the wave of renal blood flow and blood pressure was registered. During the control period $(40 \mathrm{~min}), 0.9 \% \mathrm{NaCl}$ was infused through the venous catheter. In the experimental period $(40 \mathrm{~min})$ the selective $\mathrm{L}$ type $\mathrm{Ca}^{2+}$ channel blocker Amlodipine besylate (AML) in dose $200 \mathrm{mkg} \cdot \mathrm{kg}^{-1}$ bolus followed by $50 \mathrm{mkg} \cdot \mathrm{kg}^{-1} \cdot \mathrm{h}$ infusion was applied for investigation of participation of L-type $\mathrm{Ca}^{2+}$ channels in the regulation of arterial blood pressure and renal blood flow. The arterial blood pressure (ABP) and renal blood flow (RBF) waves were recorded simultaneously via a Biopac MP150WS system. Subsequent processing of the received signals was accomplished by the Acknowledge 3.8.1. software. The spectra of the successive, resampled of $10 \mathrm{~Hz}$ data sets of systolic (SAP), diastolic (DAP), and mean (MAP) arterial pressure, as well as maximal (MAX), minimal (MIN) and mean (MEAN) values in the renal blood wave were obtained in the Lab View 3.11 program environment. In the $\mathrm{ABP}$ and RBF spectrograms the fluctuations in the low (L: 0.020-0.195 Hz), mid (M: 0.195-0.605 Hz) and high $(\mathrm{H}: 0.605-3.00 \mathrm{~Hz})$ frequencies as the percentage of total spectral power (L\%; M\% and $\mathrm{H} \%$ ) was investigated.

Statistical analysis was performed by Student's t-test. The results are presented as a $M E A N \pm$ SEM. Differences less that $\mathrm{p}<0.05$ were considered statistically significant.

\section{RESULTS}

Selective inhibition of L-type $\mathrm{Ca}^{2+}$ channels through application of Amlodipine besilate did not change mean values of ABP (Table 1), however, caused changes in the percentage participation of the low- and high-frequency components in the formation of total spectral power in spectrograms of the SAP, DAP and MAP (Figure 1). The percentage contribution of low frequency (L\%) fluctuations for SAP has risen during AML application from 14.73 $\pm 2.47 \%$ to $27.19 \pm 2.47 \%$, for DAP from $29.80 \pm 4.73 \%$ to $52.59 \pm 2.70 \%$ and for MAP from $23.29 \pm 3.67 \%$ to $41.98 \pm 3.07 \%$, p $<0.01$. The share of high frequency fluctuations $(\mathrm{H} \%)$ in the overall variability of SAP, DAP and MAP was reduced as a result of AML application: from $77.82 \pm 2.75 \%$ to $59.91 \pm$ $2.70 \%$ in the spectrograms of SAP; from 56.21 $\pm 5.51 \%$ to $27.35 \pm 2.36 \%$ in DAP 
spectrograms and in MAP spectrograms from $70.65 \pm 4.08 \%$ to $40.72 \pm 3.16 \%, \mathrm{p}<0.01$. The percentage contribution of the mid frequency (M\%) fluctuations for SAP and MAP
MARKOVA P. et al. spectrograms increased after AML application from $5.01 \pm 0.71 \%$ to $10.04 \pm 0.83 \%, \mathrm{p}<0.01$ and from $7.71 \pm 0.69 \%$ to $12.32 \pm 0.92 \%$, $\mathrm{p}<0.01$, respectively.

Table 1. Effects of selective blockade of L-type $\mathrm{Ca}^{2+}$ channels on arterial blood pressure (ABP)

$\begin{array}{crc}\text { ABP } & \text { Control } & \text { AML } \\ \text { SAP mmHg } & 120.8 \pm 4.2 & 121.6 \pm 2.0 \\ \text { DAP mmHg } & 71.2 \pm 4.4 & 77.4 \pm 4.9 \\ \text { MAP mmHg } & 87.5 \pm 4.6 & 91.0 \pm 4.2\end{array}$

Systolic (SAP), diastolic (DAP) and mean (MAP) arterial blood pressure values in control period and during selective blockade of L-type $\mathrm{Ca}^{2+}$ channels with Amlodipine besilate (AML) in dose $200 \mathrm{mkg} \cdot \mathrm{kg}^{-1}$ bolus followed by $50 \mathrm{mkg} \cdot \mathrm{kg}^{-1} \cdot \mathrm{h}$ infusion.

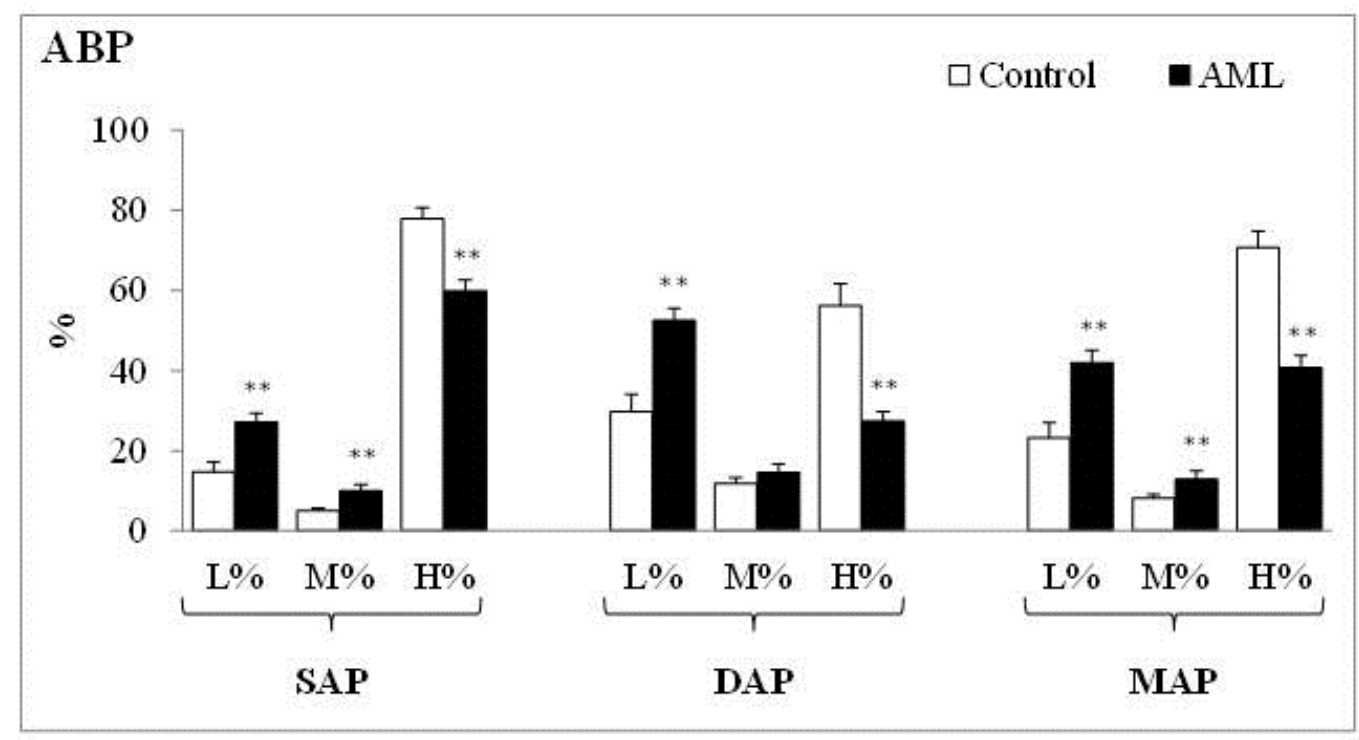

Figure 1. Percentage participation of low (L), mid (M) and high $(\mathrm{H})$ variations in the total spectral power of systolic (SAP), diastolic (DAP) and mean (MAP) arterial blood pressure (ABP) wave in control period (Control) and during intravenous administration of Amlodipine besylate (AML) in dose $200 \mu \mathrm{g} \cdot \mathrm{kg}^{-1}$ bolus injection +50 $\mu \mathrm{g} . \mathrm{kg}^{-1} . \mathrm{h}$ infusion.

** $(\mathrm{p}<0.01)$ shows statistically significant differences as a result of selective L-type $\mathrm{Ca}^{2+}$ channels blockade.

In difference to $\mathrm{ABP}$, administration of AML led to slight, but significant increase of mean values of RBF, (Table 2). The selective inhibition of L-type $\mathrm{Ca}^{2+}$ channels caused changes in the percentage distribution of $\mathrm{L} \%$ and $\mathrm{H} \%$ fluctuations in RBF spectrograms, analogous to those found in ABP spectrograms (Fig.2). An increase in the percentage participation of the low frequency in the formation of total spectral power from $9.57 \pm$ $1.08 \%$ to $24.55 \pm 3.42 \%$; from $19.29 \pm 3.64 \%$ to $35.36 \pm 3.56 \%$ and from $11.77 \pm 1.58 \%$ to 24.61 $\pm 1.95 \%$ in MAX, MIN and MEAN spectrograms of RBF was observed. The H\% fluctuations in RBF decreased in MAX spectrograms from $80.12 \pm 1.28 \%$ to $60.90 \pm 4.46 \%$ in MAX, from $64.15 \pm 3.98 \%$ to $43.99 \pm 3.97 \%$ in MIN and from $77.93 \pm$ $2.25 \%$ to $55.92 \pm 4.06 \%$ in MEAN spectrograms, $p<0.01$. In difference to $A B P$ spectrograms percentage participation of mid fluctuations M\% in generation of MAX, MIN and MEAN overall spectral variability in RBF did not change during AML application. 
Table 2. Effects of selective blockade of L-type $\mathrm{Ca}^{2+}$ channels on renal blood flow (RBF)

$\begin{array}{lll}\text { RBF } & \text { Control } & \text { AML } \\ \text { MAX ml.min }{ }^{-1} .100 \text { g b.w. } & 11.6 \pm 0.4 & 13.1 \pm 0.5^{* *} \\ \text { MIN ml.min }{ }^{-1} .100 \text { g b.w. } & 7.08 \pm 0.1 & 7.8 \pm 0.2^{*} \\ \text { MEAN ml.min }{ }^{-1} .100 \text { g b.w. } & 8.7 \pm 0.2 & 10.2 \pm 0.3^{* *}\end{array}$

Maximal (MAX), minimal (MIN) and mean (MEAN) renal blood flow values in control period and during selective blockade of L-type $\mathrm{Ca}^{2+}$ channels with Amlodipine besilate (AML) in dose $200 \mathrm{mkg} \cdot \mathrm{kg}^{-1}$ bolus followed by $50 \mathrm{mkg} \cdot \mathrm{kg}^{-1} \cdot \mathrm{h}$ infusion.

$*(p<0.05) ; * *(p<0.01)$ shows statistically significant differences as a result of selective L-type $\mathrm{Ca}^{2+}$ channels blockade.

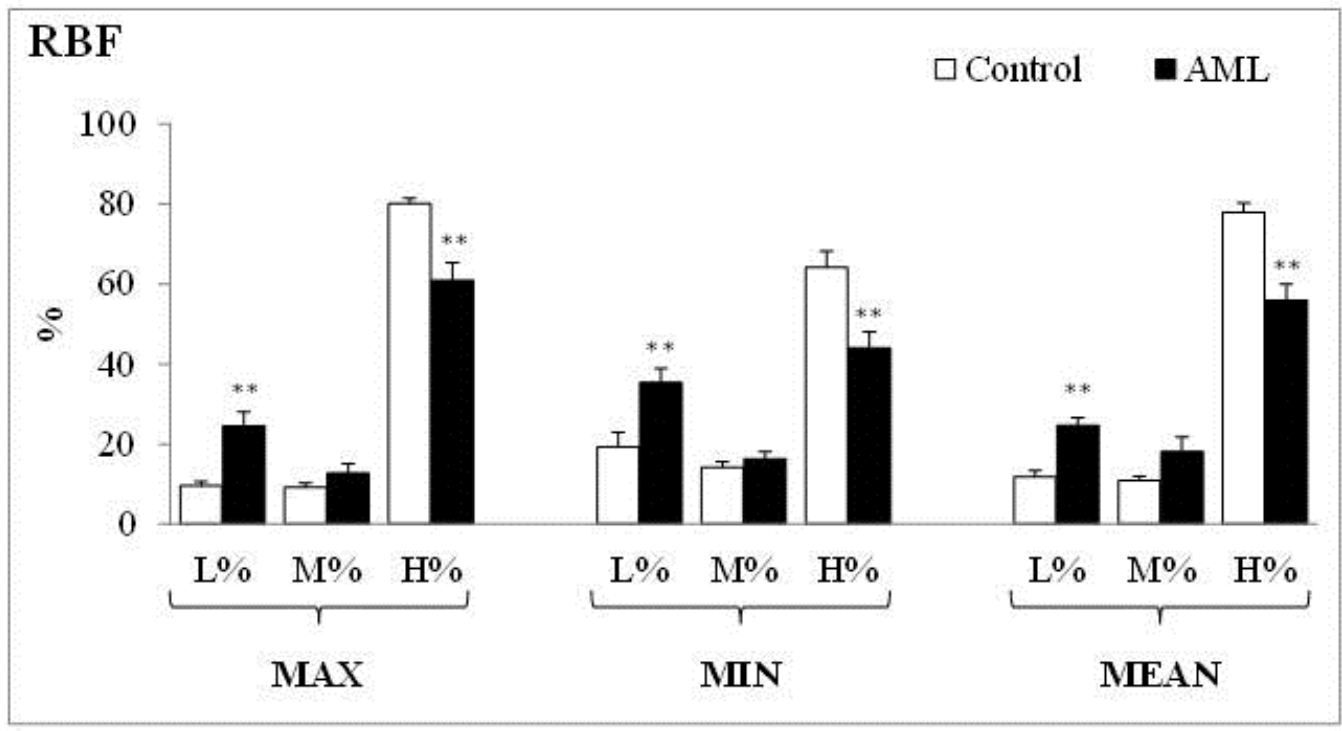

Figure 2. Percentage participation of low $(\mathrm{L})$, mid $(\mathrm{M})$ and high $(\mathrm{H})$ variations in the total spectral power of maximal (MAX), minimal (MIN) and mean (MEAN) renal blood flow (RBF) wave in control period (Control) and during intravenous administration of Amlodipine besylate (AML) in dose $200 \mu \mathrm{g}^{\mathrm{kg}} \mathrm{g}^{-1}$ bolus injection +50 $\mu \mathrm{g} . \mathrm{kg}^{-1} \cdot \mathrm{h}$ infusion.

** $(\mathrm{p}<0.01)$ shows statistically significant differences as a result of selective L-type $\mathrm{Ca}^{2+}$ channels blockade.

\section{DISSCUSION}

The results obtained in our study show an increase of percentage contribution of low frequency fluctuations in SAP, DAP and MAP spectrograms during selective blockade of Ltype $\mathrm{Ca}^{2+}$ channels. It has been established that L-type $\mathrm{Ca}^{2+}$ channels plays key role in the realization of myogenic vascular response (3, $9,12,13,14)$. In our experiments, we found a raise of $L \%$ fluctuations in RBF spectrograms. The experimental data indicated that myogenic component of dynamic autoregulation operated in the frequency below $0.2 \mathrm{~Hz}$ in renal vascular beds $(14,15)$. Our results, obtained by spectral analysis confirm the available experimental evidence for the role of myogenic vascular response in the regulation of low frequency fluctuations of blood pressure and renal blood flow (6, 9-11). During L-type $\mathrm{Ca}^{2+}$ channels blockade we found increase of percentage contribution of mid frequency fluctuations of total spectral power in SAP and MAP spectrograms. The mid frequency oscillations of blood pressure is associated mostly with sympathetic modulation of vascular tone (16, 17). It has been demonstrated that sympathetic $\alpha$-adrenergic mediated vasoconstriction is partly depends by L-type $\mathrm{Ca}^{2+}$ channels (9). It is possible that changes in M\% of total spectral power in SAP and MAP spectrograms reflected the change of sympathetic activity influenced by L-type $\mathrm{Ca}^{2+}$ channels blockade. We do not exclude the possibility of involvement of other factors with sympathetic- 
like frequency characteristics in response to diminished availability of L-type $\mathrm{Ca}^{2+}$ channels. The dose of amlodipine used in our study did not cause changes in mean values of blood pressure, but led to slight, but significant increase of mean values of RBF (Tables 1, 2). This result can be explained by the modulating influence of L-type $\mathrm{Ca}^{2+}$ channels blockade on the renal sympathetic nerves, which are widely presented in renal vascular beds. Interestingly, the share of mid frequency fluctuations of total variation in RBF did not affect as a result of amlodipine application. The sympathetic mediated changes observed in ABP spectrograms were not occur in RBF spectral characteristics. This may be a result of specific and differentiated regulation of sympathetic outflow to different vascular beds $(6,8)$. In the other hand in physiological control of renal blood flow contributed different systemic and local produced vasoactive factors $(11,17)$. We suggested that L-type $\mathrm{Ca}^{2+}$ channels blocked allows the manifestation of a slower mechanism whose effect is not reflected in the spectral profile of the RBF, but causes a decrease in the mean value of RBF. In ABP and RBF spectrograms we established decrease of $\mathrm{H} \%$ fluctuations. High frequency blood pressure fluctuation linked to respiration has been suggested to involve fluctuations of cardiac output (7). The L-type $\mathrm{Ca}^{2+}$ channels are widely distributed and are well characterized in the heart. The blockade of Ltype $\mathrm{Ca}^{2+}$ channels affected excitationcontraction coupling in cardiomyocytes and respectively cardiac output.

\section{CONCLUSION}

In our study we established redistribution of the spectral power in the low frequencies.

Our results by using a spectral method of analysis of ABP and RBF confirmed involvement of L-type $\mathrm{Ca}^{2}{ }^{+}$channels in the mediation of dynamic nature of myogenic vascular response. The L-type $\mathrm{Ca}^{2+}$ channels in different specific manner participate in the regulation of renal blood flow and arterial blood pressure.

\section{REFERENCESS}

1. Bayliss, W., On the local reactions of the arterial wall to changes of internal pressure. J Physiol, 28: 220 -231, 1902.

2. Walker, M., 3rd Harrison-Bernard, LM., Cook, AK., Navar, LG., Dynamic interaction between myogenic and TGF mechanisms in afferent arteriolar blood
MARKOVA P. et al. flow autoregulation. Am J Physiol Renal Physiol, 279: F858 -F865, 2000.

3. Davis, MJ., Hill, MA,. Signaling mechanisms underlying the vascular myogenic response. Physiol Rev, 79: 387423, 1999.

4. Beresford AP., McGibney D., Humphrey MJ., Macrae PV., Stopher DA. Metabolism and kinetics of amlodipine in man. Xenobiotic, a 18(2): 245-54,1988.

5. Akselrod S., Gordon D., Madwed JB., Snidman NC., Shannon DC., Cohen RJ., Hemodynamic regulation: investigation by spectral analysis. Am J Physiol Heart Circ Physiol, 249: H867-H875, 1985.

6. Persson PB., Modulation of cardiovascular control mechanisms and their interaction. Physiol Rev., 76(1):193244, 1996.

7. Julien C., Zhang ZQ., Cerutti C., Barres C., Hemodynamic analysis of arterial pressure oscillations in conscious rats. $J$ Auton Nerv Syst, 50:239 -252, 1995.

8. Malpas SC., Neural influences on cardiovascular variability: possibilities and pitfalls. Am J Physiol Heart Circ Physiol, 282: H6-H20, 2002.

9. Langager AM., Hammerberg BE., Rotella DL., Stauss HM.,Very low-frequency blood pressure variability depends on voltage-gated L-type $\mathrm{Ca} 2+$ channels in conscious rats. Am J Physiol Heart Circ Physiol, 292(3):H1321-7, 2007.

10. Burke M, Pabbidi MR., Farley J., Roman RJ., Molecular mechanisms of renal blood flow autoregulation. Curr Vasc Pharmacol,12(6):845-58, 2014.

11. Just A., Mechanisms of renal blood flow autoregulation: dynamics and contributions. Am J Physiol Regul Integr Comp Physiol, 292: R1-R17, 2007.

12. Furutani H., Zhang XF., Iwamuro Y., Lee K., Okamoto Y., Takikawa O.,.Fukao M., Masaki T., Miwa S., Ca2 entry channels involved in contractions of rat aorta induced by endothelin-1, noradrenaline, and vasopressin. $J$ Cardiovasc Pharmacol, 40: 265-276, 2002.

13. Wesselman JP., VanBavel E., Pfaffendorf M., Spaan JA., Voltageoperated calcium channels are essential for the myogenic responsiveness of cannulated rat mesenteric small arteries. J Vasc Res, 33: 32- 41, 1996.

14. Cupples WA., Braam B., Assessment of renal autoregulation. Am J Physiol Renal Physiol 292: F1105-F1123, 2007. 
15. Loutzenhiser R., Griffin K., Williamson G., Bidani A., Renal autoregulation: new perspectives regarding the protective and regulatory roles of the underlying mechanisms, Am J Physiol Regul Integr Comp Physiol 290: R1153-R1167, 2006.

16. Julien C., Malpas SC., Stauss HM., Sympathetic modulation of blood pressure
MARKOVA P. et al. variability. J Hypertens, 19: 1707-1712, 2001.

17. Stauss HM., Kregel KC., Frequency response characteristic of sympatheticmediated vasomotor waves in conscious rats. Am J Physiol Heart Circ Physiol, 271: H1416 -H1422, 1996. 